\title{
The Changes and System Construction of Spatial Planning from the Perspective of Policy Diffusion
}

\author{
Yuyao Wang ${ }^{1}$, Xin Wang ${ }^{1, *}$ \\ ${ }^{1}$ School of Government, Beijing Normal University, Beijing 100875, China \\ ${ }^{*}$ Corresponding author.Email: bnuzgwangxin@126.com
}

\begin{abstract}
Although China's various plans have played an active role in promoting the process of urbanization, the parallel, selfcontained, and content overlapping and conflicting issues of multi-sectoral planning hinder the effective use of spatial resources, and spatial planning system with "Multiple Planning Integration" has become a policy innovation to solve problems. From the perspective of policy diffusion theory, this study analyzes the development process of Chinese territorial planning and spatial planning and summarizes its space-time evolution characteristics and diffusion paths. The results show that in the time dimension, it has mainly experienced three stages: the formation and preliminary trial of territorial planning policies, the slow diffusion of territorial planning policies and the innovation phase of territorial and spatial planning policies, and the accelerated diffusion phase of territorial and spatial planning policies. In the spatial dimension, the proximity diffusion effect and cross-regional diffusion effect is very significant. In the policy diffusion path, vertical absorption-radiation and horizontal interactive learning are the main methods of policy diffusion. The study analyzes the development process of territorial and spatial planning from a new perspective. Based on the review of the past, we can better look forward to the future, and then provide a certain scientific basis for the establishment of territorial spatial planning system.
\end{abstract}

Keywords: spatial planning, policy diffusion, space-time evolution

\section{INTRODUCTION}

In national governance, spatial governance is an extremely important part, and spatial planning is an important part of promoting the modernization of the spatial governance system. Territorial space not only includes various resources such as land, water, minerals, biology, climate, ocean, and tourism, but also covers economic and social foundations and conditions. On May 23, 2019, the Central Committee of the Communist Party of China and the State Council established the framework of a spatial planning system in the new era, marking the construction of the spatial planning system was officially launched by issuing the "Several Opinions of the Central Committee of the Communist Party of China and the State Council on Establishing a Spatial Planning System and Supervising Implementation" (hereinafter referred to as the "Opinions"). As an important result of the reform of "Multiple Planning Integration", Spatial planning not only reflects the fundamental requirements of the construction of ecological civilization, but also reflects the practical need to transform the way of governance of spatial [1]. The construction of the spatial planning system has undergone a long-term process of development and change. From the perspective of policy diffusion, this paper discusses the time and space evolution characteristics and diffusion paths of territorial planning and spatial planning development, which can enrich the research results in related fields and provide reference for the formulation and implementation of spatial planning.

\section{LITERATURE REVIEW}

Since the 1960s, Western scholars have begun to pay attention to the diffusion of policy ideas and policy projects among governments [2]. The policy diffusion framework was proposed by Frances Stokes Berry and William D. Berry in the 1990s, using induction as the main research method to explain the differences in specific policy innovations in different states, places or countries. The theory is based on the research and analysis of policy diffusion factors and internal determinants and uses the method of event history analysis to verify the model through the analysis of 
several factors of the communication model and the internal decision model [3].

According to the chronological order and the different characteristics of each stage, Chen Fang breaks the development of the policy diffusion theory into three stages: single-factor explanation period, multiplemechanism explanation period, and tentative integrating theory explanation period [4]. Policy diffusion theory has some reference significance for China's public policy practice and research. However, due to the fundamental differences between Chinese and Western political systems, the research of policy diffusion theory by Chinese scholars has certain localization characteristics. Zhou Wang believes that China's policy diffusion process has its own characteristics and requires localized debugging of theories [5]. Wang Puqu and others proposed that China's public policy diffusion is mainly divided into four modes: hierarchical diffusion model, policy adoption and promotion model, regional and sectoral diffusion model, and leader laggard model [6]. In recent years, the policy diffusion theory has been applied to many domestic public policy studies, and the research fields have continued to expand, and the research content has been continuously deepened, such as low-rent housing policies [7], pension insurance policies, hierarchical diagnosis and treatment policies [8], urban domestic waste classification policies [9], and so on.

In 1935, Chinese geographer Hu Huanyong drew the "Aihui Tengchong Line" in his paper "The Distribution of Chinese Population", which deeply revealed the agglomeration and imbalance of land use. Therefore, optimizing the layout of spatial, properly coordinate the relationship between economy, population, environment, and resources, and planning spatial resources more efficiently have been hot issues studied by scholars for many years. The "Opinions" proposed the establishment of a spatial planning system, integrating major functional area planning, land use planning, urban and rural planning, marine functional zoning and other spatial planning into a unified territorial and spatial planning, achieving "Multiple Planning Integration" and strengthening territorial and spatial planning Regarding the guiding and restrictive role of various special plans, some scholars discuss the preparation of territorial and spatial plans from the perspective of special plans, such as marine spatial planning [10], nature reserve planning [11], energy planning [12], transportation planning [13], and so on. The "Opinions" put forward that the overall framework of spatial planning is to realize classification and establish spatial planning. Many scholars have also discussed the preparation of spatial planning at different levels based on pilot experience. Hao Qing [14] and others believe that the provincial level spatial planning has a link between the past and the next. Zhang Yun [15] and others selected Laibin, Guangxi as the research object to study the technical path of its municipal spatial planning. Chen Meizhao [16] and others proposed that village-level spatial planning is the starting point of the rural revitalization strategy and the key to the implementation of spatial planning, scholars have discussed the corresponding implementation measures and suggestions from the national level to the provincial level, to cities, counties and districts, to key villages. All levels of spatial planning pilot projects have produced their own characteristics based on the actual local conditions, and scholars have also analyzed the pilots in different regions, such as the pilots in Liuzhou City [17], Yulin City [18], Huantai County in Shandong Province [19], etc. In the era of rapid technological development, big data technology has also become an important support for territorial and spatial planning. Some scholars have conducted research and exploration, such as making full use of Internet population migration and population thermal data [20] and the establishment of an information data platform [21].

At present, the research on spatial planning is rich in content, mainly focusing on the preparation and implementation of planning. There are relatively few literatures on the formation and change process of the spatial planning system from the perspective of public policy.

\section{ANALYSIS ON THE TIME AND SPACE EVOLUTION OF SPATIAL PLANNING SYSTEM}

\subsection{The Time Evolution of Spatial Planning System}

\subsubsection{The first stage: the formation and preliminary trial stage of territorial planning policy (1980s-late 20th century)}

This stage is a period for the central government draws on foreign experience and formulates land planning policy on the basis of summarizing the problems arising from the development and utilization of land resources. It is also a period of preparation for the entire policy diffusion.

After the founding of the New China, the state organized scientific investigations and comprehensive 
surveys of natural resources, and initially grasped the quantity, quality and distribution of natural resources, laid the foundation for the next land planning work, but the planning in this period focused on development planning, light spatial planning. In the early 1980s, after summarizing the positive and negative experiences and lessons of the development and utilization of land resources since the founding of the New China, drawing on the successful experience of developed countries such as Japan, Germany, France in the development and remediation of land resources, China began to carry out territorial planning and remediation [22]. In 1987, the "Measures for the Compilation of Territorial Planning" was promulgated, which determined the main tasks of territorial planning and it became Chinese first administrative regulation on territorial planning. In 1990, the former National Planning Commission organized the compilation of the "Outline of the National Territorial Master Plan (Draft)". Although it was not approved due to institutional reforms and adjustments to the national strategy, many strategic ideas in the plan had an important impact on the subsequent compilation of spatial plans.

\subsubsection{The second stage: the slow diffusion of territorial planning policies and the innovation stage of spatial planning policies)}

\subsubsection{Slow diffusion of territorial planning policies (1998-2017).}

The salient feature of the slow diffusion stage of territorial planning policies is the slow increase in the number of pilot cities. Local governments learn from each other and make adjustments according to local conditions. This is a long-term, slow and dynamic development process.

In 1998, the State Council was reformed, and the functions of territorial planning were adjusted to the original Ministry of Land and Resources. In August 2001, the former Ministry of Land and Resources issued the "Notice on Issues Concerning the Pilot Work of Territorial Planning" and began to conduct the pilot project of territorial planning in Shenzhen and Tianjin. During this period, other provinces and cities carried out policy learning and reference. In 2003, Liaoning and Xinjiang launched pilot territorial planning, and Guangdong launched pilot territorial planning in 2004. After the 18th CPC National Congress mentioned strengthening of territorial planning, Fujian, Chongqing, Shandong, Zhejiang, Shanghai and other provinces and cities began to prepare territorial planning. With the gradual enrichment of pilot experience in various regions, the first meeting of the Leading Group for the Preparation of the National Territorial Planning Outline passed the "Working Plan for the Preparation of the National territorial Planning Outline" in September 2010 , then the preliminary research and preparation of the "National Territorial Planning Outline (2011-2030)" was officially launched. In 2013, the former Ministry of Land and Resources and the National Development and Reform Commission jointly took the lead in organizing the compilation of the National Territorial Planning Outline (2014-2030) (Draft). In May 2017, the "National Territorial Planning Outline (2016-2030)" was officially promulgated.

\subsubsection{Policy innovation stage of Spatial planning (2008-2015).}

Some problems have also arisen in the process of accelerating the development of territorial planning. Many planning departments are of obvious nature and self-contained. The contradictions and conflicts between "Multiple Planning" are large, which seriously hinder the rational use of urban and rural space resources and the sustainable economic and social development, these practical problems force the government to make policy innovations.

Local governments began to explore spontaneously with policy innovations slowly diffusion. In 2008, Yunfu City carried out the "Three-plan Integration" of land use planning, main functional zone planning and urban planning; At the end of 2008, Shanghai launched the "Two-plan Integration" of land use planning and urban planning to form the "Shanghai Planning and Land Resources Bureau". At the beginning of 2009, Wuhan City launched the "Two-plan Integration" for land use planning and urban planning and established the "Wuhan Land Resources and Planning Bureau". In August 2014, the National Development and Reform Commission, the Ministry of Land and Resources, the Ministry of Environmental Protection, and the Ministry of Housing and Urban-Rural Development jointly issued the "Notice on Carrying out the Pilot Work of "Multiple Planning Integration" in City and County" and identified 28 "Multiple Planning Integration" city and county pilot units, including 6 prefecture-level cities and 22 county-level cities. Each pilot area is in the exploratory stage, without unified policy standard, and the method system has its own characteristics. The "Overall Plan for the Reform of the Ecological 
Civilization System" issued by the central government in 2015 proposed for the first time "to build a nationally unified, interconnected, and hierarchical spatial planning system with spatial governance and spatial structure optimization as the main content and strive to resolve issues such as overlapping conflicts of spatial planning and departments, and frequent changes in local planning."

\subsubsection{The third stage: the accelerated diffusion of spatial planning policies (2015 to present).}

The main feature of this stage is the accelerated diffusion of spatial planning policies and the reshaping of the state-led spatial planning system. According to the policy diffusion theory, the central government can promote the diffusion of policies through incentives or coercive means. During this period, the high pressure of administrative instructions has become an important reason for the rapid diffusion of spatial planning policy.

In January 2017, the central government issued the "Provincial Space Planning Pilot Program", including 9 provinces including Hainan, Ningxia, Jilin, Zhejiang, Fujian, Jiangxi, Henan, Guangxi, and Guizhou, and for the first time proposed delimitation of urban, agricultural, and ecological space as well as the red line of ecological protection, permanent basic farmland and urban development boundaries ("Three districts and Three lines"), this clarifies the basic concept of spatial planning. The pilot provinces used the provincial-level spatial planning pilot as an opportunity to actively carry out the "Multiple Planning Integration" pilot program to explore the ideas of city and county spatial planning. In March 2018, the State Council reformed and established the Ministry of Natural Resources, which made the establishment of a spatial planning system and supervision of implementation as one of its important responsibilities, and basically ended the confusion of multiple spatial planning. Based on the pilot experience at the provincial, city and county levels, the central government has accelerated the construction of the spatial planning system. On May 23, 2019, the "Several Opinions of the Central Committee of the Communist Party of China and the State Council on Establishing a Spatial Planning System and Supervising Implementation" was issued, marking the official launch of the construction of spatial planning system and clarifying the territorial boundaries of the "five levels, three categories, and four systems" The spatial planning system includes the five levels of national, provincial, municipal, county, and township, with three types of overall planning, detailed planning, and special planning, and four operating systems: the preparation and approval system, the implementation supervision system, the regulatory policy system, and the technical standard system. So far, the organization, concepts, elements, and levels of the spatial planning under the national overall planning have been clarified, and all regions have begun to develop plans according to local conditions.

\subsection{The spaces evolution of the territorial space planning system}

\subsubsection{Proximity effect}

In the process of policy diffusion, geographic factors play an important role, manifesting in the exchange of information and material circulation. In the space area that is closer to the policy innovation place, it may be earlier to obtain relevant institutional innovation information and adopt the innovation system, while those with a relative distance in areas far away, the effect of innovation policies will be perceived later, and the adoption time will be later.

During the period of territorial planning, the "Notice on Issues Concerning the Pilot Work of Land Planning" issued in 2001 carried out pilot land planning work in Shenzhen and Tianjin. In 2003, Liaoning and Xinjiang also joined the pilot team. Shenzhen's rich pilot experience has led to policy learning and imitation in surrounding areas. Guangdong Province was also included in the pilot province in 2004. In 2009, China also initiated the preparation of territorial planning for the Henan Central Plains City Group, Guangxi Beibu Gulf Economic Zone, and Hunan Changzhutan Economic Zone to play the role of driving learning in the economic zone. Along with the development of pilot projects in these areas, Wuhan City Circle and other areas in Guangxi have also started pilot work on land planning.

\subsubsection{Cross-regional effect}

There is an imbalance in development between regions in China, which is reflected in the differences in the fiscal capacity of local governments and the ability of regional economic development. The development differences between regions have caused the potential energy difference of policy learning and diffusion, which means that regions with backward policies will learn from advanced regions. 
In 2008, Shanghai and Wuhan successively merged the original land and planning departments and carried out the "Two-plan Integration". Afterwards, Zhejiang, Chongqing, Guangzhou and other places explored and carried out the "Two-plan Integration", "Four-plan Overlap" and "Three-plan Integration", the diffusion of spatial planning policies during this period was concentrated in megacities and developed areas. In 2014, 28 cities and counties across the country began to carry out the "Multiple Planning Integration" pilot program. In 2017, 9 provinces including Hainan, Ningxia, Jilin, Zhejiang, Fujian, Jiangxi, Henan, Guangxi, and Guizhou started the provincial-level spatial planning pilot. In 2019, The "Opinions" marked the gradual diffusion of policies across the country. The cross-regional effects of the diffusion of spatial planning policies are embodied in the process of spontaneous local exploration, stateauthorized pilot projects, and the reshaping of the stateled spatial planning system.

\section{THE POLICY DIFFUSION OF SPATIAL PLANNING SYSTEM}

Looking back at the history of territorial planning and the construction of the spatial planning system, the vertical pilot promotion from bottom to top, the vertical influence from top to bottom, and the horizontal competition and learning are the main paths for policy diffusion. The vertical diffusion path can be summarized as "absorption-radiation". In the absorption stage, the superior government evaluates and adjusts the policy implementation effect of governments at lower levels. Only approved policies can continue to be implemented. In the radiation stage, the Superior government uses administrative instructions to require governments at lower levels to implement it.

\subsection{Vertical absorption: pilot promotion from bottom to top}

Policy trials have always been a policy innovation model with Chinese characteristics, reflecting the interaction from bottom to top between local governments and the central government. With the rapid development of territorial planning, the problems of parallel planning, self-contained systems, and conflicts between plans have become more serious, hindering the optimal allocation of local land resources and economic development, and practical problems have forced local governments to make policy innovations. Local governments began to carry out reforms and explorations spontaneously. For example, the "Three- plan Integration" and "Two-plan Integration" reforms in Yunfu, Wuhan and Shanghai. The main purpose of reforms is to strive for spatial management policies and powers "from bottom to top", expand the scale of urban construction land, and provide a land foundation for urban development.

\subsection{Vertical radiation: hierarchical diffusion from top to bottom}

As a unitary country, China has obvious centralization and hierarchy among government agencies. In the five-level government system consisting of the central government, provinces, municipalities and autonomous regions, prefecture-level cities, countylevel cities, and townships, the superior government adopts a policy and then it will quickly diffuse to the corresponding departments of governments at lower levels through administrative instructions, and governments at lower levels will implement it, and the policy will be fully rolled out. In 2014, based on the spontaneous pilot experience in multiple locations, the state began to authorize reform pilots and identified 28 "Multiple Planning Integration" city and county pilot units, including 6 prefecture-level cities and 22 countylevel cities, starting in 2017 pilot projects for provinciallevel spatial planning in 9 provinces and cities will be carried out, and the construction of planning system will be launched nationwide in 2019. The method of central administrative instructions endows the legitimacy of Spatial planning, which speeding up the implementation and changes of policies, and policies gradually diffuse across the country from top to bottom.

\subsection{Horizontal interaction: competitive learning between regions}

It can be seen from the process of the pilot spatial planning that competition and learning among regions is undoubtedly an important driving force for policy diffusion. Local governments have both competition and learning under the pressure of the central government's administrative instructions and tasks. The actual problems within the local government will also force them to make policy innovations.

\section{CONCLUSION}

The establishment of a nationally unified, clear-cut, scientific and efficient spatial planning system is a necessary measure for the scientific layout of production space, ecological space and living space. From 
territorial planning to the formation of the spatial planning system, policies have a significant diffusion effect across the country, which is a long-term dynamic process. From the theoretical perspective of policy diffusion, this paper explores the time-space evolution mechanism and diffusion path of territorial planning and spatial planning. It is mainly divided into three stages in the time dimension, namely the formation and preliminary trial of territorial planning policy, the slow diffusion of territorial planning policies, the innovation phase of territorial and spatial planning policies, and the accelerated diffusion phase of territorial and spatial planning policies. There are obvious proximity diffusion effects and cross-regional diffusion effects in the space dimension. In terms of policy diffusion paths, there is a horizontal and vertical parallel diffusion method mainly including vertical absorption-radiation and horizontal interactive learning, which have promoted the diffusion of policies across the country.

At present, with the promulgation of the "Opinions", the national spatial planning has clarified the goal, that is, to basically establish a national spatial planning system by 2020 and initially form a national spatial development and protection "map"; by 2025, a land spatial development and protection system based on spatial planning and by means of unified use control will be formed; a land spatial pattern with more intensive and efficient production space, suitable living space and beautiful ecological space will be basically formed by 2035. In this process, how to ensure the smooth landing and implementation of the policy and achieve good results are issues that need further research.

\section{REFERENCES}

[1] Z.J. Dong, Ten relations of territorial planning in the new era, Resources Science, vol. 41, no. 9, 2019, pp. 1589-1599. DOI: 10.18402/resci.2019.09.01

[2] L.Z. Wang, and R. Pang, Temporal and Spatial Evolution Mechanism and Policy Diffusion Path of China's Public Policy: A Study of the Implementation and Changes of River-Chief System, Chinese Public Administration, VOL. 5, 2018, pp. 63-69. DOI: 10.3782/j.issn.10060863.2018.05.10

[3] G.Q. Yang, Public Policy, Beijing Normal University Press, 2009
[4] F. Chen, Evolvement of Public Diffusion, Chinese. Chinese Public Administration, VOL. 6, 2014, pp. 99-104. DOI: 10.3782/j.issn.1006-0863.2014.06.19

[5] W. Zhou, Policy diffusion theory and China's policy experiment: Enlightenment and adjustment, Journal of Sichuan Administration Institute, VOL. 4, 2012, pp. $\quad 43-46$. DOI: $10.3969 /$ j.issn.10086323.2012.04.010

[6] P.Q. Zhou, and X.J. Lai, A Study on the Model and Mechanism of Public Policy Diffusion in China, Journal of Peking University (Philosophy and Social Sciences), vol. 50, no.6, 2013, pp. 14-23.

[7] D.G. Zhu, and Z.J. Hu, On the Ways to Promote Policy Diffusion by the Central Government-A Case Study of Low-rent Housing Policy, Journal of Northeastern University (Social Science), vol. 19, no.4, 2017, pp. 378-384. DOI: 10.15936/j.cnki.1008-3758.2017.04.008

[8] L. Tao, and H.L. Liang, Study on the path and impetus of China's hierarchical healthcare system reform: An analysis based on the policy diffusion theory, Chinese Journal of Health Policy, vol. 12, no.6, 2019, pp. 9-14. DOI: 10. 3969 /j. issn. 16742982. 2019.06. 002

[9] X.J. Wang, Research on the status quo and influencing factors of the diffusion of municipal solid waste classification policy, Coastal Enterprises, vol. 1, 2018, pp.30-34. DOI: 10.3969/j.issn.1007-7723.2018.01.009

[10] Q.B. Di, and X. Han, Review and Prospects of Marine Spatial Planning Research in China from the Perspective of Territorial Spatial Planning, Journal of Ocean University of China (Social Sciences), vol. 5, 2019, pp. 59-68. DOI: 10.16497/j.cnki.1672-355X.201905007

[11] Z.C. Zhao, and R. Yang, On the Positioning of Protected Area Planning in National Spatial Planning, Chinese Landscape Architecture, vol. 8, 2019, pp. 5-11. DOI: $10.19775 /$ j.cla.2019.08.0005

[12] Y.H. Zhu, Research on energy planning in Guangzhou's land space planning, City \& House, vol. 7, 2019, pp. 60-62. DOI: 10.3969/j.issn.10066659.2019.07.015

[13] X.Y. Ma, and X.F. Jiang, Transportation Planning in National Territory Spatial Planning in Large Metropolitan Areas: A Case Study of Guangzhou, 
Urban Transport of China, vol. 4, 2019, pp. 11-16. DOI:10.13813/j.cn11-5141/u.2019.0403

[14] Q. Hao, Z.M. Feng, and G. H. Yuan, Thoughts on the Compilation of Provincial Territory Spatial Planning, Natural Resource Economics of China, vol. 1, 2018, pp. 29-33. DOI: 10.19676/j.cnki.1672-6995.000007

[15] Y. Zhang, H.F. Zhu, J.X. Mao, and X.C. Pan, National Land Use Planning Technique Study, Planners, vol. 11, 2015, pp. 52-57. DOI: 10.3969/j.issn.1006-0022.2015.11.009

[16] M.Z. Chen, R.B. Zheng, X. Zheng, Exploration and innovation of rural land spatial planning in China, China Land, vol. 4, 2019, pp. 37-39. DOI: 10.13816/j.cnki.ISSN1002-9729.2019.04.12

[17] H.L. Ye, Practice and Exploration on the construction of territorial spatial planning system in Guangxi, China Land, vol. 9, 2019, pp. 4-11. DOI: 10.13816/j.cnki.ISSN1002-9729.2019.09.02

[18] Y.T. Zhao, and Q.Q. Ge, Territorial Spatial Planning in the Context of Multiple Planning Integration: Taking Yulin Pilot as a Case, Land and Resources Information, vol. 8, 2018, pp. 22-29. DOI: CNKI: SUN: GTZQ.0.2018-08-005

[19] J. Lin, Z.Y. Qiao, and Y.X. Wu, Analysis of The One Blueprint of the Multiple Plans Integration: A Case Study of Huantai County, Shandong Province, Urban Development Studies, vol. 6, 2017, pp.47-52. DOI: CNKI: SUN: CSFY.0.2017-06-007

[20] Y. Yuan, Y.H. Wang, X.X. Zhou and X.L. Zhang, Conceptual Exploration and Practical Application on Flexibility and Efficiency of Territory Spatial Planning Making from the Perspective of Big Data, China Land Science, vol. 33, no. 1, 2019, pp.9-16. DOI: $10.11994 /$ zgtdkx.20190110.154214

[21] Y.J. Miao, The Application of Big Data of Geographic Information in Land Space Planning, Construction \& Design for Engineering, vol. 14, 2019 , pp.251-252.

DOI: 10.13616/j.cnki.gcjsysj.2019.07.316

[22] Z.X. Huang, and L.X. Huang, The logic of territorial spatial planning evolving, Public Administration and Policy Review, vol. 6, 2019, pp.40-49. DOI: 10.3969/j.issn.20954026.2019.06.004 